
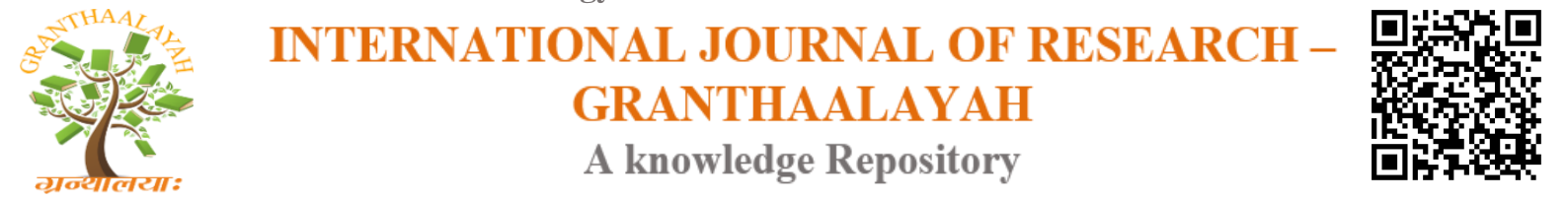

RAST - 17

\title{
STUDIES ON GENERALISED UNSTABLE FUNCTIONS IN TOPOLOGICAL SPACES
}

\author{
L. Vijilius Helena Raj ${ }^{1}$, G. Srinivasa ${ }^{2}$ \\ ${ }^{1,2}$ New Horizon College of Engineering, Outer Ring Road, Marathahalli, Bangalore, 560 103, \\ India
}

DOI: https://doi.org/10.5281/zenodo.803422

\begin{abstract}
In this paper we bring in a new class of functions called $g^{*} \Lambda$ irresolute function and contra $g^{*} \Lambda$ irresolute function, where $\mathrm{g}^{*} \Lambda$ irresolute function is a weaker form of $\mathrm{g}^{*} \Lambda$ continuous function and contra $g^{*} \Lambda$ irresolute function is a weaker form of contra $g^{*} \Lambda$ continuous function.

Keywords: $\mathrm{g}^{*} \Lambda$ Irresolute Functions and Contra $\mathrm{g}^{*} \Lambda$ Irresolute Function.

2010 Math Subject Classification: $54 \mathrm{C} 10$

Cite This Article: L. Vijilius Helena Raj, and G. Srinivasa. (2017). "STUDIES ON GENERALISED UNSTABLE FUNCTIONS IN TOPOLOGICAL SPACES." International Journal of Research - Granthaalayah, 5(4) RAST, 45-51. https://doi.org/10.5281/zenodo.803422.
\end{abstract}

\section{Introduction}

In 1986, Maki [6] continued the work of Levine and Dunham on generalized closed sets and closure operators by introducing the notion of $\Lambda$-sets in topological spaces. In $2008 \mathrm{M}$. Caldas, S. Jafari and T. Noiri [8] introduced $\Lambda$ generalized closed sets $(\Lambda \mathrm{g}, \Lambda-\mathrm{g}, \mathrm{g} \Lambda)$ and their properties. They also studied the concept of $\lambda$ closed maps. Recently, many authors investigated some new maps and their notions via $\lambda$ open sets and $\lambda$ closed sets. In 2007 M.Caldas,S.Jafari and T. Navalagi [10] introduced the concept of $\lambda$ irresolute maps. The notion of irresolute functions [7] was introduced and investigated by M.Caldas in 2000.

In this direction we establish a new class of function called $\mathrm{g}^{*} \Lambda$ irresolute function and contra $\mathrm{g}^{*} \Lambda$ irresolute function. This new classes are the weaker forms of their continuous functions. That is $g^{*} \Lambda$ irresolute function is a weaker form of $g^{*} \Lambda$ continuous function and contra $g^{*} \Lambda$ irresolute function is a weaker form of contra $g^{*} \Lambda$ continuous function. Here we investigate some of their fundamental properties and the connections between these maps and other existing topological maps are studied. 
Throughout this paper $(\mathrm{X}, \tau),(\mathrm{Y}, \sigma)$ and $(\mathrm{Z}, \eta)$ (or simply $\mathrm{X}, \mathrm{Y}$ and $\mathrm{Z}$ ) will always denote topological spaces on which no separation axioms are assumed unless explicitly stated. $\operatorname{Int}(\mathrm{A}), \mathrm{Cl}(\mathrm{A}), \operatorname{Int} \lambda(\mathrm{A}), \mathrm{Cl} \lambda(\mathrm{A}), \mathrm{g}^{*} \Lambda \mathrm{Cl}(\mathrm{A})$ and $\mathrm{g}^{*} \Lambda \operatorname{Int}(\mathrm{A})$ denote the interior of $\mathrm{A}$, closure of $A$, lambda interior of $A$, lambda closure of $A, g^{*} \Lambda$ closure of $A$ and $g^{*} \Lambda$ Interior of $A$ respectively.

\section{Preliminary Definitions}

Let us recall some definitions in sequel which is useful for this paper.

Definition 2.1 A subset A of a space $(X, \tau)$ is called

1) A semi open set [14] if $\mathrm{A} \subset \mathrm{Cl}(\operatorname{Int}(\mathrm{A}))$

2) A pre open set [1]if $\mathrm{A} \subset \operatorname{Int}(\mathrm{Cl}(\mathrm{A}))$

3) A regular open set [1] if $\mathrm{A}=\operatorname{Int}(\mathrm{Cl}(\mathrm{A}))$

The complement sets of semi open (respectively preopen and regular open) are called semi closed sets (respectively pre closed and regular closed). The semi closure (respectively pre closure) of a subset $\mathrm{A}$ of $\mathrm{X}$ denoted by $\mathrm{sCl}(\mathrm{A}),(\mathrm{pCl}(\mathrm{A}))$ is the intersection of all semi closed sets (pre closed sets) containing A.

Definition 2.2 A topological $\operatorname{space}(\mathrm{X}, \tau)$ is said to be

1) a generalized closed [3] if $\mathrm{Cl}(\mathrm{A}) \subset \mathrm{U}$, whenever $\mathrm{A} \subset \mathrm{U}$ and $\mathrm{U}$ is open in $\mathrm{X}$.

2) a subset $A$ of a space $X$ is called $\lambda$-closed [6] if $A=B \cap C$, where $B$ is a $\Lambda$-set and $\mathrm{C}$ is a closed set.

3) a subset $\mathrm{A}$ of $\mathrm{X}$ is said to be a $\Lambda \mathrm{g}$ closed set [8] if $\mathrm{Cl}(\mathrm{A}) \subset \mathrm{U}$ whenever $\mathrm{A} \subset \mathrm{U}$, where $\mathrm{U}$ is $\lambda$ open in $X$.

4) a subset $A$ of $X$ is said to be a $g^{*} \Lambda$ closed set [21] if $\mathrm{Cl}_{\lambda}(\mathrm{A}) \subset \mathrm{U}$ whenever $\mathrm{A} \subset \mathrm{U}$, where $\mathrm{U}$ is semi open in $\mathrm{X}$.

The complement of above closed sets is called its respective open sets.

The $g^{*} \Lambda$ closure (respectively closure, $\lambda$ closure) of a subset $A$ of $X$ denoted by $\mathrm{g} * \Lambda \mathrm{Cl}(\mathrm{A}),(\mathrm{Cl}(\mathrm{A}), \mathrm{Cl} \lambda \mathrm{A})$ is the intersection of all $\mathrm{g}^{*} \Lambda$ closed sets (closed sets, $\lambda$ closed sets) containing A.

The $\mathrm{g}^{*} \Lambda$ interior (respectively interior, $\lambda$ interior) of a subset $A$ of $X$ denoted by $\mathrm{g}^{*} \Lambda \operatorname{Int}(\mathrm{A}),(\operatorname{Int}(\mathrm{A}), \operatorname{Int} \lambda(\mathrm{A}))$ is the union of all $\mathrm{g}^{*} \Lambda$ open sets (open sets, $\lambda$ open sets) containing A.

Definition 2.3 A space $(\mathrm{X}, \tau)$ is called

(i)[15] a $T_{1 / 2}$ Space if every g closed subset of $X$ is closed in $X$, (ii)[13]a $T \hat{g}$ Space if every $\hat{g}$ closed subset of $X$ is closed in $X$, (iii)[13] $T_{b}$ space if every $g^{*}$ - closed subset of $X$ is closed in $\mathrm{X}$. 


\section{Lemma 2.4 [3]}

1) Every $\Lambda$-set is a $\lambda$-closed set,

2) Every open and closed sets are $\lambda$-closed sets.

Proposition 2.5 [21] In a topological space $(X, \tau)$, the following properties hold:

1) Every closed set is $g^{*} \Lambda$ closed,

2) Every open set is $g^{*} \Lambda$ closed,

3) Every $\lambda \operatorname{closed}\left(\lambda\right.$ open) set is $g^{*} \Lambda \operatorname{closed}\left(g^{*} \Lambda\right.$ open $)$,

4) Union (intersection) of $g^{*} \Lambda$ closed ( $g^{*} \Lambda$ open) sets is not $g^{*} \Lambda \operatorname{closed}\left(g^{*} \Lambda\right.$ open),

5) In $T_{1}$ space every $g^{*} \Lambda$ closed set ( $g^{*} \Lambda$ open) is $\lambda$ closed( $\lambda$ open),

6) In Partition space every $g^{*} \Lambda$ closed( $g * \Lambda$ open) set is $g$ closed(g open),

7) In a door space every subset is $\mathrm{g}^{*} \Lambda$ closed ( $\mathrm{g}^{*} \Lambda$ open), and

8) In $T_{1 / 2}$ space every subset is $g^{*} \Lambda$ closed( $g^{*} \Lambda$ open).

Definition 2.6 A function $\mathrm{f}:(\mathrm{X}, \tau) \rightarrow(\mathrm{Y}, \sigma)$ is called

1) $[8] \lambda$ closed if $f(F)$ is $\lambda$ closed in $(Y, \sigma)$ for every $\lambda$ closed set $F$ of $(X, \tau)$,

2) [14] semi continuous if $f^{-1}(V)$ is semi open in $(X, \tau)$ for every open set $V$ in $(Y, \sigma)$,

3) $[3,9] \lambda$ continuous if $f^{-1}(V)$ is $\lambda$ open ( $\lambda$ closed) in $(X, \tau)$ for every open (closed) set $\mathrm{V}$ in $(\mathrm{Y}, \sigma)$,

4) [2] contra continuous if $f^{-1}(V)$ is open (closed) in $(X, \tau)$ for every closed (open) set $\mathrm{V}$ in $(\mathrm{Y}, \sigma)$,

5) [5] contra semi continuous if $f^{-1}(V)$ is semi open (semi closed) in (X, $\tau$ ) for every closed (open) set $\mathrm{V}$ in $(\mathrm{Y}, \sigma)$,

6) [11] contra $\lambda$ continuous map if $f^{-1}(V)$ is $\lambda$ open $(\lambda$ closed) in $(X, \tau)$ for every closed (open) set $\mathrm{V}$ in $(\mathrm{Y}, \sigma)$,

7) [18] irresolute if for any semi open set $S$ of $(Y, \sigma), f^{-1}(S)$ is semi open in $(X, \tau)$,

8) [1] gc irresolute if the inverse images of $g$ closed sets in $(Y, \sigma)$ are $g$ closed in $(X, \tau)$,

9) [10] $\lambda$ irresolute if the inverse image of $\lambda$ open sets in $Y$ are $\lambda$ open in $(X, \tau)$

\section{Lemma $2.7[11]$}

A space $(X, \tau)$ is said to be $\lambda S$-space if every $\lambda$ open subset of $X$ is semi open in $X$. A space $(X, \tau)$ is said to be $\lambda$-space if every $\lambda \operatorname{closed}(\lambda$ open) subset of $X$ is closed(open) in $\mathrm{X}$.

M.Caldas and S.Jafari introduced $\lambda \mathrm{T}_{0}, \lambda-\mathrm{T}_{1}, \lambda-\mathrm{T}_{2}$ and $\lambda \mathrm{R}_{0}$ spaces. It is also proved that a space $X$ is $\lambda T_{1}$ if and only if $X$ is $T_{0}$ and also observed that $T_{0}=\lambda-T_{0}=\lambda-T_{1}=\lambda-T_{2}$.

Recall that a topological space $X$ is said to be

1) $[10] \lambda T_{0}\left(\operatorname{resp} \lambda-T_{1}\right)$ if for $x, y \in X$ such that $x=y$ there exist a $\lambda$ - open set $U$ of $X$ containing $\mathrm{x}$ but not $\mathrm{y}$ or (resp and) a $\lambda$-open set $\mathrm{V}$ of $\mathrm{X}$ containing $\mathrm{y}$ but not $\mathrm{x}$.

2) $[10] \lambda T_{2}$ if for $x, y \in X$ such that $x=y$ there exist a $\lambda$ - open set $U$ of $X$ containing $\mathrm{x}$ and a $\lambda$-open set $\mathrm{V}$ of $\mathrm{X}$ containing $\mathrm{y}$ such that $\mathrm{U} \cap \mathrm{V}=\varnothing$.

3) $[10] \lambda R_{0}$ if every set contains the closure of its singletons. 


\section{3. $g^{*} \Lambda$ Irresolute Map}

\section{Definition 3.1}

1) A map $f:(X, \tau) \rightarrow(Y, \sigma)$ is called $g^{*} \Lambda$ irresolute map if the inverse image of each $\mathrm{g}^{*} \Lambda$ closed set in $\mathrm{Y}$ is $\mathrm{g}^{*} \Lambda$ closed in $\mathrm{X}$.

2) A map $\mathrm{f}:(\mathrm{X}, \tau) \rightarrow(\mathrm{Y}, \sigma)$ is called contra $\mathrm{g}^{*} \Lambda$ irresolute map if the inverse image of each $\mathrm{g}^{*} \Lambda$ closed set in $\mathrm{Y}$ is $\mathrm{g}^{*} \Lambda$ open in $\mathrm{X}$.

Theorem 3.2 A map $f:(X, \tau) \rightarrow(Y, \sigma)$ is $g^{*} \Lambda$ irresolute if and only if the inverse image of each $\mathrm{g}^{*} \Lambda$ open set in $\mathrm{Y}$ is $\mathrm{g}^{*} \Lambda$ open in $\mathrm{X}$.

Proof: Let $U$ be a $g^{*} \Lambda$ open set in $Y$. Then $\mathrm{XrU}$ is $\mathrm{g}^{*} \Lambda$ closed set in $\mathrm{Y}$. By definition $\mathrm{f}^{-1}(\mathrm{X} \boldsymbol{r} \mathrm{U})=\mathrm{Yr}_{\boldsymbol{r}} \mathrm{f}^{-1}(\mathrm{U})$ is $\mathrm{g}^{*} \Lambda$ closed set in $\mathrm{X}$. Thus $\mathrm{f}^{-1}(\mathrm{U})$ is $\mathrm{g}^{*} \Lambda$ open set in $\mathrm{X}$.

Converse is easy to prove.

Theorem 3.3 A map $\mathrm{f}:(\mathrm{X}, \tau) \rightarrow(\mathrm{Y}, \sigma)$ is contra $\mathrm{g}^{*} \Lambda$ irresolute if and only if the inverse image of each $\mathrm{g}^{*} \Lambda$ open set in $\mathrm{Y}$ is $\mathrm{g}^{*} \Lambda$ closed in $\mathrm{X}$.

Proof: Let $U$ be a $g^{*} \Lambda$ open set in $Y$. Then $X r U$ is $g^{*} \Lambda$ closed set in $Y$. By definition $\mathrm{f}^{-1}(\mathrm{X} \mathbf{r} \mathrm{U})=\mathrm{Yr}^{-1}(\mathrm{U})$ is $\mathrm{g}^{*} \Lambda$ open set in $\mathrm{X}$. Thus

In similar lines Converse is proved.

Definition 3.4 A topological space $(X, \tau)$ is said to be a $g^{*} \Lambda$ space if the union (intersection) of $g^{*} \Lambda$ closed $\left(g^{*} \Lambda\right.$ open) sets is $g^{*} \Lambda$ closed $\left(g^{*} \Lambda\right.$ open)and the intersection(union) of $g^{*} \Lambda$ closed ( $g^{*} \Lambda$ open) sets is $g^{*} \Lambda$ closed ( $g^{*} \Lambda$ open).

Theorem 3.5 For a bijective function $\mathrm{f}:(\mathrm{X}, \tau)-\rightarrow(\mathrm{Y}, \sigma)$, the following are equiv- alent. Assume that $(X, \tau)$ is a $g^{*} \Lambda$ space.

(i) $f$ is contra $g * \Lambda$ irresolute.

(ii) For every $g^{*} \Lambda$ open subset $F$ of $Y, f^{-1}(F)$ is $g^{*} \Lambda$ closed in $X$.

(iii) For each $x \in X$ and each $g^{*} \Lambda$ closed subset $F$ of $Y$ with $f(x) \in F$, there exist a $g^{*} \Lambda$ open set $\mathrm{U}$ of $\mathrm{X}$ with $\mathrm{x} \in \mathrm{U}, \mathrm{f}(\mathrm{U}) \subseteq \mathrm{F}$.

Proof:

(i) $\longleftrightarrow$ (ii) theorem [3.3]

(i) $\Longrightarrow$ (iii) Let $F$ be any $g^{*} \Lambda$ closed subset of $Y$ and let $f(x) \in F$ where $x \in X$.

Then by (ii) $f^{-1}(F)$ is $g^{*} \Lambda$ open in $X$. Also $x \in f^{-1}(F)$. Let $U=f^{-1}(F)$. Then

$\mathrm{U}$ is $\mathrm{g}^{*} \Lambda$ open set containing $\mathrm{x}$ and $\mathrm{f}(\mathrm{U}) \subseteq \mathrm{F}$.

(iii) $\Rightarrow$ (i) Let $F$ be any $g^{*} \Lambda$ closed subset of $Y$. If $x \in f^{-1}(F)$, then $f(x) \in F$.

Hence by (iii), there exist a $g^{*} \Lambda$ open set $U_{x}$ of $X$ with $x \in U_{x}$ such that $f\left(U_{x}\right) \subseteq F$. Then $\mathrm{f}^{-1}(\mathrm{~F})=\mathrm{U}\left\{\mathrm{U}_{\mathrm{x}}: \mathrm{x} \in \mathrm{f}^{-1}(\mathrm{~F})\right\}$ and hence by assumption $\mathrm{f}^{-1}(\mathrm{~F})$

is $\mathrm{g}^{*} \Lambda$ open in $\mathrm{X}$.

Theorem 3.6 Every $g^{*} \Lambda$ irresolute function is contra $g^{*} \Lambda$ continuous function Proof: Let a function $\mathrm{f}:(\mathrm{X}, \tau) \rightarrow(\mathrm{Y}, \sigma)$ be $\mathrm{g}^{*} \Lambda$ irresolute and let $\mathrm{F}$ be a open set in $(\mathrm{Y}, \sigma)$, by proposition $2.5 \mathrm{~F}$ is also $\mathrm{g}^{*} \Lambda$ closed in $\mathrm{Y}$. Since $\mathrm{f}:(\mathrm{X}, \tau)-\rightarrow(\mathrm{Y}, \sigma)$ is a $\mathrm{g}^{*} \Lambda$ irresolute function, $f^{-1}(F)$ is $g^{*} \Lambda$ closed in $(X, \tau)$. Thus $f$ is a contra $g^{*} \Lambda$ continuous function. 
[Raj et. al., Vol.5 (Iss.4: RAST), April, 2017]

ICV (Index Copernicus Value) 2015: 71.21

Recent Advances in Science \& Technology
ISSN- 2350-0530(O), ISSN- 2394-3629(P)

IF: 4.321 (CosmosImpactFactor), 2.532 (I2OR) InfoBase Index IBI Factor 3.86

Converse need not be true as seen from the following example.

Example 3.7 Let $\mathrm{X}=\mathrm{Y}=\{\mathrm{a}, \mathrm{b}, \mathrm{c}, \mathrm{d}, \mathrm{e}\}$ and $(\mathrm{X}, \tau)=\{\varnothing, \mathrm{X},\{\mathrm{a}\},\{\mathrm{b}\},\{\mathrm{a}, \mathrm{b}\}$, $\{b, c\},\{a, b, c\},\{b, c, d\},\{a, b, c, d\},\{b, c, d, e\}\},(Y, \sigma)=\{\varnothing, Y,\{a\},\{b, c, d\},\{a, b, c, d\}$, $\{b, c, d, e\}\}$. The identity function $f:(X, \tau) \rightarrow(Y, \sigma)$ is a contra $g^{*} \Lambda$ continuous function but not $\mathrm{g}^{*} \Lambda$ irresolute functions as $\mathrm{A}=\{\mathrm{b}, \mathrm{d}\}$ is $\mathrm{g}^{*} \Lambda$ closed in $(\mathrm{Y}, \sigma)$ but $\mathrm{f}^{-1}(\mathrm{~A})=\{\mathrm{b}, \mathrm{d}\}$ is not $\mathrm{g}^{*} \Lambda$ closed in $(\mathrm{X}, \tau)$.

Theorem 3.8 Every contra $g^{*} \Lambda$ irresolute function is contra $g^{*} \Lambda$ continuous function.

Proof: Let a function $\mathrm{f}:(\mathrm{X}, \tau) \rightarrow(\mathrm{Y}, \sigma)$ be contra $\mathrm{g}^{*} \Lambda$ irresolute and let $\mathrm{F}$ be a open set in $(\mathrm{Y}, \sigma)$, by proposition $2.5 \mathrm{~F}$ is also $\mathrm{g}^{*} \Lambda$ open in $\mathrm{Y}$. Since $\mathrm{f}:(\mathrm{X}, \tau) \rightarrow(\mathrm{Y}, \sigma)$ is a contra $\mathrm{g}^{*} \Lambda$ irresolute function, $\mathrm{f}^{-1}(\mathrm{~F})$ is $\mathrm{g}^{*} \Lambda$ closed in $(\mathrm{X}, \tau)$. Thus $\mathrm{f}$ is a contra $\mathrm{g}^{*} \Lambda$ continuous function. Converse need not be true as seen from the following example.

Example 3.9 Let $X=Y=\{a, b, c, d, e\}$ and $(X, \tau)=\{\varnothing, X,\{a\},\{b\},\{a, b\}$, $\{b, c\},\{a, b, c\},\{b, c, d\},\{a, b, c, d\},\{b, c, d, e\}\},(Y, \sigma)=\{\varnothing, Y,\{a\},\{b, c, d\},\{a, b, c, d\}$, $\{b, c, d, e\}\}$. The identity function $f:(X, \tau) \rightarrow(Y, \sigma)$ is a contra $g^{*} \Lambda$ continuous function but not contra $g^{*} \Lambda$ irresolute functions as $A=\{b, d\}$ is $g^{*} \Lambda$ closed in $(\mathrm{Y}, \sigma)$ but $\mathrm{f}^{-1}(\mathrm{~A})=\{\mathrm{b}, \mathrm{d}\}$ is not $\mathrm{g}^{*} \Lambda$ open in $(\mathrm{X}, \tau)$.

In a similar way we can prove the following theorems.

\section{Theorem 3.10}

Every $g^{*} \Lambda$ irresolute function is $g^{*} \Lambda$ continuous function.

Every contra $g^{*} \Lambda$ irresolute function is $g^{*} \Lambda$ continuous function

Converse of the above statements need not be true as seen from the following examples.

Example 3.11 Let $\mathrm{X}=\mathrm{Y}=\{\mathrm{a}, \mathrm{b}, \mathrm{c}, \mathrm{d}, \mathrm{e}\}$ and $(\mathrm{X}, \tau)=\{\varnothing, \mathrm{X},\{\mathrm{a}\},\{\mathrm{b}\},\{\mathrm{a}, \mathrm{b}\},\{\mathrm{a}, \mathrm{b}, \mathrm{e}\}$, $\{a, b, d, e\},\{a, b, c, e\}\},(Y, \sigma)=\{\varnothing, Y,\{a\},\{b\},\{a, b\},\{c, d\},\{a, c, d\},\{b, c, d\},\{c, d . e\}$, $\{a, b, c, d\},\{a, c, d, e\},\{b, c, d, e\}\}$. The identity function $f:(X, \tau) \rightarrow(Y, \sigma)$ is a $g^{*} \Lambda$ continuous function but not $g^{*} \Lambda$ irresolute functions as $A=\{b, c\}$ is $g^{*} \Lambda$ closed in $(Y, \sigma)$ but $f^{-1}(A)=\{b, c\}$ is not $g^{*} \Lambda$ closed in $(X, \tau)$.

Remark 3.13 $\mathrm{g}^{*} \Lambda$ irresolute function and $\lambda$ irresolute function are independent. It can be seen from the following example.

Example 3.14 Let $X=Y=\{a, b, c, d, e\}$ and $(X, \tau)=\{\varnothing, X,\{a\},\{b, c, d\},\{a, b, c, d\}\},(Y, \sigma)=$ $\{\varnothing, Y,\{a\},\{b\},\{a, b\},\{b, c\},\{a, b, c\},\{b, c, d\},\{a, b, c, d\},\{b, c, d, e\}\}$. The identity function $\mathrm{f}:(\mathrm{X}, \tau) \rightarrow(\mathrm{Y}, \sigma)$ is $\mathrm{g}^{*} \Lambda$ irresolute functions but not $\lambda$ irresolutefunction as $\mathrm{A}=\{\mathrm{a}, \mathrm{c}, \mathrm{d}\}$ is $\lambda$ closed in $(\mathrm{Y}, \sigma)$ but $\mathrm{f}^{-1}(\mathrm{~A})=\{\mathrm{a}, \mathrm{c}, \mathrm{d}\}$ is not $\lambda$ closedin $(\mathrm{X}, \tau)$.

Example 3.15 Let $X=Y=\{a, b, c, d, e\}$ and $(X, \tau)=\{\varnothing, X,\{a\},\{b\},\{a, b\},\{b, c\}$, $\{a, b, c\},\{b, c, d\},\{a, b, c, d\},\{b, c, d, e\}\},(Y, \sigma)=\{\varnothing, Y,\{a\},\{b, c, d\},\{a, b, c, d\}\}$. The identity function $\mathrm{f}:(\mathrm{X}, \tau) \rightarrow(\mathrm{Y}, \sigma)$ is $\lambda$ irresolute function but not $\mathrm{g}^{*} \Lambda$ irresolute function as $A=\{b, d\}$ is $g^{*} \Lambda$ closed in $(Y, \sigma)$ but $f^{-1}(A)=\{b, d\}$ is not closed in $(X, \tau)$. 
Theorem 3.16 Every $g^{*} \Lambda$ irresolute function $f:(X, \tau) \rightarrow(Y, \sigma)$ is $\lambda$ irresolute function if $(\mathrm{X}, \tau)$ is a $\mathrm{T}_{1}$ space.

Proof: Let $\mathrm{F}$ be a $\lambda$ closed set in $(\mathrm{Y}, \sigma)$. By proposition $2.5 \mathrm{~F}$ is a $\mathrm{g}^{*} \Lambda$ closed set in $(Y, \sigma)$. Since $f$ is a $g^{*} \Lambda$ irresolute function, $f^{-1}(F)$ is $g^{*} \Lambda$ closed in $(X, \tau)$. Now $f^{-1}(F)$ is $\lambda$ closed in $\mathrm{X}$ by proposition 2.5, as $(\mathrm{X}, \tau)$ is $\mathrm{T}_{1}$ space .Thus $\mathrm{f}$ is a $\lambda$ irresolute function.

In a similar way we get,

Theorem 3.17 Every $\lambda$ irresolute function $f:(X, \tau) \rightarrow(Y, \sigma)$ is $g^{*} \Lambda$ irresolute function if $(\mathrm{Y}, \sigma)$ is a $\mathrm{T}_{1}$ space.

Proof: Proof follows by proposition 2.5 .

Theorem 3.18 Every $g^{*} \Lambda$ irresolute function $f:(X, \tau)-\rightarrow(Y, \sigma)$ is generalised continuous function if $(\mathrm{X}, \tau)$ is partition space.

Proof: Proof follows as in partition-space every $\mathrm{g}^{*} \Lambda$ closed set is $\mathrm{g}$ closed (by proposition 2.5).

Theorem 3.19 Every $g^{*} \Lambda$ irresolute function $\mathrm{f}: \mathrm{X} \rightarrow \mathrm{Y}$ is semi continuous func- tion, if $\mathrm{X}$ is a $T_{1}$ space and $\lambda S$ - space.

Proof: Let $\mathrm{F}$ be a open set in $(\mathrm{Y}, \sigma)$. By proposition $2.5 \mathrm{~F}$ is a $\mathrm{g}^{*} \Lambda$ open set in $\mathrm{Y}$. Since $\mathrm{f}:(\mathrm{X}, \tau) \rightarrow(\mathrm{Y}, \sigma)$ is $\mathrm{g}^{*} \Lambda$ irresolute function, we get $\mathrm{f}^{-1}(\mathrm{~F})$ is $\mathrm{g}^{*} \Lambda$ open in $(\mathrm{X}, \tau)$. By proposition $2.5 \mathrm{f}^{-1}(\mathrm{~F})$ is $\lambda$ open in $\mathrm{X}$, as $(\mathrm{X}, \tau)$ is $\mathrm{T}_{1}$ space. Also since $(\mathrm{X}, \tau)$ is a $\lambda \mathrm{S}$ space $\mathrm{f}^{-1}(F)$ is semi open in $X$ by lemma 2.7. Thus $f$ is a semi continuous function.

Theorem 3.20 Every $\mathrm{g}^{*} \Lambda$ irresolute function $\mathrm{f:X} \rightarrow \mathrm{Y}$ is continuous function, if $\mathrm{X}$ is a $\mathrm{T}_{1}$ space and $\lambda$ - space.

Proof: It follows as in $\lambda$ space every $\lambda$ open set is open ( by lemma 2.7 ).

Lemma 3.21 [21] Let $F \subseteq A \subseteq X$, where $A$ is open in $X$. If $F$ is $g^{*} \Lambda$ closed in $\mathrm{X}$, then $\mathrm{F}$ is $\mathrm{g}^{*} \Lambda$ closed in $\mathrm{A}$.

Theorem 3.22 If a function $f:(X, \tau) \rightarrow(Y, \sigma)$ is a $g^{*} \Lambda$ irresolute function and $A$ is a open subset of $X$, where $X$ is assumed to be a $g^{*} \Lambda$ space, then the restriction $f_{A}: A \rightarrow Y$ is also $\mathrm{g}^{*} \Lambda$ irresolute..

Proof: Let $\mathrm{V}$ be a $\mathrm{g}^{*} \Lambda$ closed set of $\mathrm{Y}$ and $\mathrm{A}$ be a open subset of $\mathrm{X}$. As every open set is $\mathrm{g}^{*} \Lambda$ closed by proposition 2.5, A is $\mathrm{g}^{*} \Lambda$ closed in $\mathrm{X}$. Since $\mathrm{f}$ is $\mathrm{g}^{*} \Lambda$ irresolute $\mathrm{f}^{-1}(\mathrm{~V})$ is $\mathrm{g}^{*} \Lambda$ closed in $X$. By assumption we have $f^{-1}(V) \cap A$ is $g^{*} \Lambda$ closed in $X$. Since $f^{-1}(V) \cap A \subseteq A \subseteq$ $\mathrm{X}$ where $\mathrm{A}$ is a open subset of $\mathrm{X}$, by lemma

$3.21 \mathrm{f}^{-1}(\mathrm{~V}) \cap \mathrm{A}=\left(\mathrm{f}_{\mathrm{A}}^{-1}(\mathrm{~V})\right)$ is $\mathrm{g}^{*} \Lambda$ closed in $\mathrm{A}$. Thus the restriction $\mathrm{f}_{\mathrm{A}}: \mathrm{A} \rightarrow \mathrm{Y}$ is $\mathrm{g}^{*} \Lambda$ irresolute.

\section{Conclusion}

We believe that topological structure will be an important base for modification of knowledge extraction and processing. The notions of sets and functions in topological spaces, ideal topological spaces, minimal spaces and ideal minimal spaces are extensively developed and used 
[Raj et. al., Vol.5 (Iss.4: RAST), April, 2017]

ICV (Index Copernicus Value) 2015: 71.21

Recent Advances in Science \& Technology
ISSN- 2350-0530(O), ISSN- 2394-3629(P)

IF: 4.321 (CosmosImpactFactor), 2.532 (I2OR)

InfoBase Index IBI Factor 3.86

in many engineering problems, information systems, particle physics, computational topology and mathematical sciences. By researching generalizations of closed sets in various fields in general topology, some new separation axioms have been founded and they turn out to be useful in the study of digital topology. Therefore, all sets defined in this paper will have many possibilities of applications in digital topology and computer graphics

\section{References}

[1] Arockiarani, K. Balachandranand J. Dontchev Some Characterizations of gp-irresolute and gpcontinuous maps between topological spaces,Mem.Fac.Sci.Kochi Univ.(Math)20(1999),93-104.

[2] J.Dontchev, contra-continuous functions and S-closed spaces, Int.J.Math.Math.Sci 19 (1996), 303-310.

[3] Francisco G Arenas, Julian Dontchev and Maxmillian Ganster, On $\lambda$-sets and the dual of generalized continuity,Question answers GEN.Topology 15(1997)3-13

[4] Jin Han Park, Yong Beom Park and Bu Young Lee, On gp closed sets and pre gp continuous functions, Indian. J. pure appl. Math vol 3(1) :3-12, January 2002.

[5] J.Dontchev and T. Noiri, contra-semicontinuous functions, Math Pan-nonica 10 (1999), 159-168.

[6] H.Maki ,Generalised $\Lambda$-sets and the associated closure operator, The spe-cial issue in Commemoration Of Prof.Kazusada IKEDS Retirement,1 oct (1986),139-146.

[7] Miguel Calda Cueva, S.Jafari and T.Noiri ,Weak and strong forms of irresolute maps,Internat.J.Math.and Math. Sci.,Vol.23,No.4,(2000),253-259.

[8] M.Caldas, S.Jafari and T.Noiri ,On $\Lambda$-generalised closed sets in topo- logical spaces,Acta Math. Hungar,118(4)(2008),337-34.

[9] M.Caldas, and Jafari, S,On some low separation axioms via $\lambda$ open and $\lambda$ closure operator.Rend.Circ.Mat.Di.Palermo 54,2 (2005),195-208.

[10] M.Caldas,S.Jafari and T.Navalgi,More on $\lambda$-closed sets in topological spaces, Revista Colombina de Mathematics,Vol 41 (2007) 2,355-369.

[11] M.Caldas,Ekici,S.Jafari and Noiri,S,On the class of contra $\lambda$ contin- uous functions.Ann.Univ.Sci.Budapest Sec Math 49(2006),75-86.

[12] M.K.R.S.VeeraKumar,g*- Closed Sets in topological space, Mem. Fac, Sci.Kohi Univ.(Math), 21(2000), 1-19.

[13] M.K.R.S Veera Kumar, On g^ closed sets in topological spaces, Bull Ala- habad.Soc18(2003)99112.

[14] N.Levine,Semi-open sets ans semi continuity in topological spaces, Amer. Math. Monthly, 70(1963), 36-41.

[15] N.Levine, Generalized closed sets in topology, Rend.Circ.Mat.Palermo,19(1970),89-96.

[16] Parithosh Bhattacharyya AND B.K.Lahiri On semi generalized closed sets in topology, Indian Journal of Mathematics, Vol 29(1987)375-382.

[17] P.Sundaram,H.Maki and K.Balachandran Semi-Generalised Contin- uous Maps and Semi-T1/2 spaces,Bulletine of Fukuoka University of Educa- tion,vol,40,part III, 33-40(1991).

[18] R Devi, H. Maki And K. Balachandran, Semi Gener-Alized closed Maps And Generalized semi Closed Maps, Mem.fac.kochi.univ.ser.a(math),14(1993).

[19] Saeid Jafari and Takashi Noiri, On contra-Precontinuous functions, Bull.Malaysian Math.Sc.Soc (second series)25(2002),115-128.

[20] S.S.Benchalli g?-Pre Regular and g?-pre Normal spaces, international Mathamatical Forum, 4, 2009, no.48, 2399-2408.

[21] S.P.Missier,Vijilius H Raj g* $\Lambda$ closed sets in topological spaces Inter- national journal of General Topology Vol. 5,Nos 1-2 January-December 2012, pp. 33-44,0973-6471.

\footnotetext{
*Corresponding author.

E-mail address: vijilius@gmail.com
} 